\title{
Tagesnotizen und Personalien
}

Dr. Hethey, Oberarzt an der Kgl. Universitäts-Augenklinik in Berlin, hat den I 'rofessortitel erhalten.

Priv.-Dozent Dr. Fleischer in Tubingen wurde zum Professor extraord. ernannt, a. o. Prof.

Lodato in Siena in gleicher Eigensohaft nach Palermo berufen.

Es habilitierten sich: Dr. Philamotr in Odessa, Dr. Bressanin in Turin.

$\mathrm{G}^{1} / 8$ storben sind: Generalarzt Dr. Seggel in München, Prof. Dr. Ludivig Laqueur in Strassburg i. Els., Dr. Hotz, früher Professor am Rush Medical College in Chicago, Dr. Simon Snell, Prof, der Augenheilkunde zu Sheffield.

Druckfehler-Berichtigung.

I. In der im Märzheft abgedmckten Arbeit von Dr. E. Hornicker soil $\theta$ s auf S. 219, Zeile 15 von oben heissen: ${ }^{\wedge}$, ,ooo ø1 Yi3 (statt ${ }^{\wedge}$ iioooo $\mathrm{cm} 3$ ).

Um EIns $\beta$ ndung von Separatabdrücken wird gebeten. V $\beta$ rantwortlich $\theta \Gamma ~ R \beta d a k t \beta u r:$ Prof. Kuhnt in Bomi a. Pvh. 